\title{
Comparative AAPOS Validation of the Birefringent Amblyopia Screener with Isolated Small-Angle Strabismus
}

\section{Robert W Arnold (DD}

Alaska Blind Child Discovery, Alaska Children's Eye and Strabismus,

Anchorage, AK, USA

\section{Video abstract}

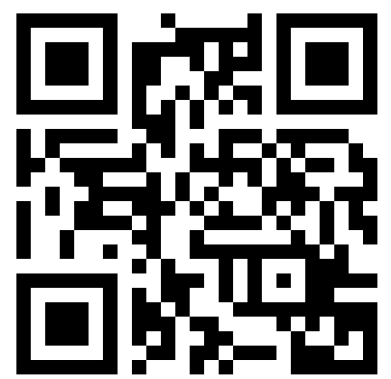

Point your SmartPhone at the code above. If you have a $Q R$ code reader the video abstract will appear. Or use: https://youtu.be/tM4UmGCiUtU
Correspondence: Robert W Arnold Alaska Blind Child Discovery, Alaska Children's Eye and Strabismus, 3500 Latouche \#280, Anchorage, AK 99508 , USA

$\mathrm{Tel}+\mid 907561-1917$

$\mathrm{Fax}+1907563-5373$

Email eyedoc@alaska.net
This article was published in the following Dove Press journal: Clinical Ophthalmology

Background: The Rebion blinq binocular birefringent ocular alignment screener was recently commercially released, but it did not yet have validation by American Association for Pediatric Ophthalmology and Strabismus (AAPOS) uniform guidelines.

Methods: Children and adults from a high-risk eye practice had screening by blinq with validation by AAPOS 2003 guidelines. Then, the blinq was compared to the Adaptica 2WIN with CR corneal reflex strabismus estimation by AAPOS 2003 guidelines plus additional efforts to identify patients with diminished binocularity.

Results: Blinq in 100 patients compared to 2003 AAPOS amblyopia risk factors (ARF) had sensitivity $67 \%$, specificity $75 \%$ and PPV of $82 \%$. Both blinq and 2 WIN were completed by 87 patients median age 6.5 years. Sensitivity, specificity and positive predictive value (PPV) for blinq were $75 \%, 68 \%$ and $81 \%$ whereas 2 WIN had $91 \%, 68 \%$ and $84 \%$. The blinq referred two young patients with isolated, small-angle strabismic amblyopia that $2 \mathrm{WIN}$ refractive function passed.

Conclusion: Despite its non-refractive design to identify binocular foveation, blinq performed well with refractive and strabismic uniform risk factors and a PPV greater than $80 \%$. Clinical Trials Registry: NCT04195711.

Keywords: birefringent, photoscreening, amblyopia, fixation instability, amblyopia risk factor, strabismus

\section{Introduction}

Binocular objective portable retinal birefringent screening became commercially available late in 2019. Conceived and developed by Drs. David Hunter and David Guyton since 1991, 1,2 this device recently called "blinq" (Rebion, Boston, MA) seeks to determine whether a patient can consistently align both visual axes on a small target or not. ${ }^{3}$

Instrument-based amblyopia screening has been available for more than two decades. Some devices employ near-coaxial flash to produce analyzable, refractionrelated pupillary crescents. One such infrared, on-site interpreted photoscreener is the 2WIN (Adaptica, Padova, Italy). Adaptica also developed an infrared transmitting occluder for the measurement of intermittent and constant strabismus by Hirschberg analysis ${ }^{4}$ so the 2 WIN with CR function provides appropriate comparison with blinq since they both screen for issues related to ocular misalignment.

The vision screening committee of the American Association for Pediatric Ophthalmology and Strabismus (AAPOS) developed and published uniform guidelines for the detection of refractive and strabismic amblyopia risk factors (ARFs). The 2013 
update to AAPOS uniform guidelines rendered infant and toddler ARFs more specific in an attempt to reduce falsepositive referrals while the older triad in 2013 guidelines closely resembles the non-age dependent 2003 guidelines. Some older patients capable of giving a reliable assessment of stereopsis and ocular suppression were compared to blinq binocular foveation and therefore the non-age-dependent 2003 guidelines were selected. The Rebion blinq had not yet been critically analyzed based on the uniform AAPOS standards. For strabismus, blinq was compared to $2 \mathrm{WIN}$ with the CR corneal reflex function with uniform ARFs and additional efforts to select patients without binocular fusion.

\section{Methods}

This prospective evaluation of clinical tests (NCT04195711) had an institutional review by Providence Hospital and complied with HIPAA and the Declaration of Helsinki. Responsible parents/adults provided signed informed consent and youth younger than 18 years, and those older than 7 years gave written assent for participation in the study. Parental written consent was obtained for linked videos used for educational purposes. Access to de-identified raw data will be maintained at http://www.abcd-vision.org/refer ences/blinq\%202WIN\%20de-ID\%20ABCD.pdf

As a part of a new or follow-up comprehensive eye examinations, patients were screened with two novel objective devices according to AAPOS Uniform guidelines. ${ }^{5,6}$ The primary outcome was bling compared to ageindependent 2003 AAPOS guidelines. Following the dry refraction, alignment (cover test) and sensory testing, cycloplegic refraction was performed 30 or more minutes after cyclopentolate $1 \%$ drops. In cooperative patients, sensory tests including Worth 4-dot, Stereo Fly and PDI Check were performed to characterize binocularity. For younger patients, binocular function was estimated by Bruckner Test and 4-base out prism cover.

Each patient was screened with a recently commercially released blinq screener according to the manufacturer's recommendations. The bling can yield initial interpretation of "pass" or "refer" but also "timed out" or "inconclusive" which, according to manufacturer instructions should be evaluated as if a "refer." An example of blinq birefringent screening is shown in this video: https:// vimeo.com/robertarnold/blinq2wincr.

Patients were screened with the binocular infrared autorefractor 2WIN (software version V5.0 171018 without Kaleidos protective housing) according to manufacturer guidelines. For ocular alignment confirmation, the
CR corneal reflex component of $2 \mathrm{WIN}$ photoscreener (Adaptica, Padova Italy) was used. ${ }^{4}$ Refractive referral criteria were not age-stratified and are anisometropia $\geq 1.50 \mathrm{D}$, cylinder $\geq 1.75 \mathrm{D}$, hyperopia $\geq 2.25 \mathrm{D}$ and myopia $\geq 4$.5D. Strabismus referral from the $2 \mathrm{WIN}$ CR function was $>5$ PD tropia. A video demonstrating the infrared occluder on the $2 \mathrm{WIN}$ is shown in this video: https:// vimeo.com/robertarnold/cr2win.

The Rebion bling is a unique screening method and therefore we sought to provide appropriate uniform and unique validation. In addition to non-age stratified AAPOS 2003 Uniform guidelines, we collected all cases characterized by constant or persistent strabismus whether large- or small angle employing cover test, 4 base out test, Bruckner Test and 2WIN CR function. Binocular function was tested with Stereo Fly, Worth-Dot (Stereo Optical, Chicago) and also with the autostereoscopic stereo test on PDI Check (PDI Check, Anchorage) as well as monocular near visual acuity and suppression. ${ }^{7}$ Methods of retinal videographic analysis of fixation instability were not available for this study. 8,9

\section{Results}

One hundred patients aged $9 \pm 10$ years, median 6.5 years were screened by blinq before confirmatory exam. The prescreening probability of 2003 AAPOS amblyopia risk factors was $66 \%$. Consistent with manufacturer guidelines, the 12 "timed out" and 1 inconclusive results were counted as "refer" yielding a sensitivity of $67 \%$, a specificity of $75 \%$ and a positive predictive value of $82 \%$ for amblyopia risk factors (Table 1 top half). Of 51 patients diagnosed with refractive amblyopia, blinq timed out in 7, referred 26, passed 17 and defined one as "inconclusive." Of 31 patients with strabismic amblyopia, blinq timed out on 5, referred 22 , passed 3 and declared "inconclusive" in one.

Eighty-seven patients were screened by both blinq and 2 WIN. Sixteen were referred from photoscreen and 14 had developmental delays (autism, Downs, fetal alcohol). By 2003 AAPOS uniform guidelines, 28 had refractive amblyopia risk factors and 15 had strabismus while 13 had both refractive plus strabismic risk factors. The prescreening prevalence of risk factors in these pediatric eye and strabismus patients was $64 \%$.

The second half of Table 1 gives validation statistics for both devices. The blinq had 13 screenings for which the interpretation "timed out" and one as inconclusive. The average age for "timed out" blinq interpretations was 3.4 years with range $0.7-8$ years. The $2 \mathrm{WIN}$ had three screenings for which no interpretation reading was obtained. As per blinq manufacturer 
Table I Validation Statistics Comparing Rebion Blinq "Blinq" To AAPOS 2003 Uniform Guidelines (Top) and Then Compared To Adaptica 2WIN with CR Strabismus Estimation "CR2"

\begin{tabular}{|c|c|c|c|c|c|c|c|c|c|c|c|}
\hline & & & $x+$ & $X-$ & & & & & & & \\
\hline & & $\mathrm{sc}+$ & A & B & & & & & & & \\
\hline & & sc - & C & D & & & & & & & \\
\hline & & Sc i & $E$ & $F$ & & & & & & & \\
\hline exam & screen & A & B & C & D & $\mathrm{E}$ & $\mathrm{F}$ & sens & spec & PPV & $\mathrm{n}$ \\
\hline 2003 & blinq i & 37 & 8 & 18 & 24 & II & 2 & $67 \%$ & $75 \%$ & $82 \%$ & 100 \\
\hline exam & screen & A & B & C & D & $\mathrm{E}$ & $\mathrm{F}$ & sens & spec & PPV & $\mathrm{n}$ \\
\hline 2003 & blinq & 42 & 10 & 14 & 21 & & & $75 \%$ & $68 \%$ & $81 \%$ & 87 \\
\hline 2003 & CR2 & 51 & 10 & 5 & 21 & & & $91 \%$ & $68 \%$ & $84 \%$ & 87 \\
\hline 2003 & blinq i & 33 & 8 & 14 & 21 & 9 & 2 & $70 \%$ & $72 \%$ & $80 \%$ & 87 \\
\hline 2003 & CR2i & 49 & 9 & 5 & 21 & 2 & 1 & $91 \%$ & $70 \%$ & $84 \%$ & 87 \\
\hline strab + & blinq i & 35 & 6 & 20 & 15 & 9 & 2 & $64 \%$ & $71 \%$ & $85 \%$ & 87 \\
\hline strab + & CR2i & 54 & 4 & 8 & 18 & 2 & I & $87 \%$ & $82 \%$ & $93 \%$ & 87 \\
\hline Ambly & blinq i & 37 & 8 & 18 & 24 & 11 & 2 & $73 \%$ & $71 \%$ & $83 \%$ & 100 \\
\hline Ambly & CR2i & 49 & 9 & 5 & 21 & 2 & 1 & $91 \%$ & $68 \%$ & $84 \%$ & 87 \\
\hline
\end{tabular}

Notes: "i" indicates inconclusive interpretations. Sensitivity is "sens," specificity "spec" and positive predictive value "PPV". "Prev" is the prescreening probability. In addition to exam criteria from the American Association of Pediatric Ophthalmology and Strabismus (AAPOS) refractive and strabismic risk factors "2003" additional cases were included with sensory, optical or motor evidence of diminished binocularity "strab +." X+ and X- are true or false confirmatory exam findings while sc + , sc- and sci are screening refer, screening pass and screening inconclusive. The final comparison ("Ambly") is with all cases defined as either strabismic and/or refractive amblyopia 20/40 or worse or two inter-eye lines difference.

guidelines, these inconclusive interpretations were considered as referrals. In addition to 2003 guideline risk factors, an effort was made to select all patients who may not have been binocular.

By 2003 guidelines, blinq had sensitivity 75\%, specificity $68 \%$ and positive predictive value $81 \%$ compared to 2 WIN with corneal reflex: sensitivity $91 \%$, specificity $68 \%$ and PPV 84\%. Adding cases with presumed limited binocularity, blinq had sensitivity $64 \%$, specificity $71 \%$ and PPV of $85 \%$ while 2 WIN with CR function had sensitivity $87 \%$, specificity $82 \%$ and PPV 93\%.

Two patients were particularly instructive. The first was an 11-year-old girl with amblyopia recently detected by her local optometrist. She had no history of strabismus surgery and no eye exam or spectacle wear before age nine. Her visual acuity with $+0.75+0.25 \times 99$ right and $+1.25+0.25 \times 80$ left eye was 20/20+ and 20/40- with 10 PD constant esotropia. She had 800 $\mathrm{s}$ of arc Stereo Fly and suppressed Worth 4-dot distance. She had positive 4 base out prism test and a positive Brückner Reflex. On PDI Check she had stereo of 280 seconds of arc and near monocular acuities of 20/20 and 20/320. She passed the $2 \mathrm{WIN}$ refractive screening but was consistently referred by the Rebion blinq. The second instructive patient was a 6-yearold boy whose mom thought she might occasionally see his eyes cross. His cycloplegic refraction was right eye +0.75 sphere yielding 20/20 and left eye $+0.25+0.50 \times 105$ yielding 20/32. He suppressed left distance, right near on Worth 4-dot and resolved 400-s arc stereo. Cover test showed 10 PD 
esotropia with positive 4 Prism base out over left eye and the left eye showed positive Bruckner Test. 2 WIN refraction passed with -0.25 sph right eye and $-0.25+1.00 \times 72$ left eye, and the CR function showed a 9.5 prism diopter esotropia left. Rebion blinq was consistently "refer."

\section{Conclusion}

Even though the Rebion blinq employs a birefringent technology that is not specifically designed to detect the refractive error, it performed favorably in detecting refractive and strabismic amblyopia risk factors defined by the AAPOS uniform standard in a high-risk cohort from a pediatric eye practice. A positive predictive value greater than $80 \%$ is important to pediatricians, parents and pediatric ophthalmologists who are all motivated to reduce false-positive referrals. Due to the fact that many children compensate for their cycloplegic refractive and intermittent strabismic risk factors, $100 \%$ sensitivity AAPOS screening is not ideal, ${ }^{10}$ especially if continuous casefinding is employed as in American Academy of Pediatrics guidelines vision screening. ${ }^{11}$

A strength of this validation is that it was done using industry-standard, AAPOS uniform guidelines in a high-risk cohort of children and some adults. The older patients were able to confirm binocular status whereas the vision screening devices are designed for early detection of amblyopia so therapy can be more effective. Another strength of this study was the inclusion of two patients with isolated, constant small-angle strabismic amblyopia - a condition regarded as quite rare, but both consistently detected by Rebion blinq. A weakness of this study was that it did not focus on routine, young child screening. The PPV for blinq in this high-risk group was reasonable. One recent poster with blinq on 300 preschoolers showed referral rate 17\% with PPV of $12 \%^{12}$ but further study on predictive value needs to be done on groups of young children with routine community prevalence of amblyopia risk factors (ie, less than $21 \%$ ). Another weakness of our study was that no patients with nystagmus were included.

The Rebion blinq offers a unique technology that can identify patients who are not simultaneously foveating with both eyes. It may be particularly useful in early identification of strabismic and mixed mechanism amblyopia, however interpretation "timed out" was fairly common for our youngest children. While many cases of refractive amblyopia can be successfully treated with spectacles, blinq may identify which children require more intense, anti-suppression therapy such as patching. As a part of computer-transferred blinq results, the foveating eye in a referral is identified- a very important point that should be included as an option for in-device reporting. The referral rate and PPV from routine, community preschool screening needs to be clarified.

\section{Disclosure}

Dr. Arnold is a board member and President of PDI Check that developed a vision screening game for the Nintendo 3DS and Glacier Medical Software that markets ROP Check cloudbased NICU monitoring software. Dr. Arnold coordinates the Alaska Blind Child Discovery which has received discounted instruments from several vendors. Dr. Arnold is an investigator and protocol developer for the Pediatric Eye Disease Investigator Group. Dr Arnold has a patent PDI Check pending to Robert Arnold and Alex Damarjian. The author reports no other conflicts of interest in this work.

\section{References}

1. Hunter DG, Shah AS, Sau S, Nassif D, Guyton DL. Automated detection of ocular alignment with binocular retinal birefringence scanning. Appl Opt. 2003;42:3047-3053. doi:10.1364/AO.42.003047

2. Gramatikov BI, Irsch K, Wu YK, Guyton DL. New pediatric vision screener, part II: electronics, software, signal processing and validation. Biomed Eng Online. 2016;15:15. doi:10.1186/s12938016-0128-7

3. Jost RM, Yanni SE, Beauchamp CL, et al. Beyond screening for risk factors: objective detection of strabismus and amblyopia. JAMA Ophthalmol. 2014;132:814-820. doi:10.1001/jamaophthalmol.2014. 424

4. Arnold SL, Arnold AW, Sprano JH, Arnold RW. Performance of the 2 WIN photoscreener with "CR" strabismus estimation in high risk patients. Am J Ophthalmol. 2019;207:195-203. doi:10.1016/j. ajo.2019.04.016

5. Donahue SP, Arthur B, Neely DE, Arnold RW, Silbert D, Ruben JB. Guidelines for automated preschool vision screening: a 10-year, evidence-based update. $J$ AAPOS. 2013;17:4-8. doi:10.1016/j. jaapos.2012.09.012

6. Donahue S, Arnold R, Ruben JB. Preschool vision screening: what should we be detecting and how should we report it? Uniform guidelines for reporting results from studies of preschool vision screening. J AAPOS. 2003;7:314-316. doi:10.1016/S1091-8531(03)00182-4

7. Smith KA, Arnold AW, Sprano JH, Arnold SL, Arnold RW. Performance of a quick screening version of the nintendo 3DS PDI check game in patients with ocular suppression. J Pediatr Ophthalmol Strabismus. 2019;56:234-237. doi:10.3928/01913913-20190502-01

8. Kelly KR, Cheng-Patel CS, Jost RM, Wang YZ, Birch EE. Fixation instability during binocular viewing in anisometropic and strabismic children. Exp Eye Res. 2019;183:29-37. doi:10.1016/j.exer.2018.07.013

9. Birch EE, Subramanian V, Weakley DR. Fixation instability in anisometropic children with reduced stereopsis. $J$ AAPOS. 2013;17:287-290. doi:10.1016/j.jaapos.2013.03.011

10. Arnold RW. Amblyopia risk factor prevalence. J Pediatr Ophthalmol Strabismus. 2013;50:213-217. doi:10.3928/01913913-20130326-01

11. Donahue SP, Baker CN, Committee on P, et al. Procedures for the evaluation of the visual system by pediatricians. Pediatrics. 137;2016:1-9. doi:10.1542/peds.2015-3597

12. Shah SS, Jimenez JJ, Rozema E, Nguyen MK, Fong DS, Mehta AM. Validation of the Pediatric Vision Scanner in a Normal Preschool Population (Poster PO358). San Francisco, CA: American Academy of Ophthalmology; 2019. 


\section{Publish your work in this journal}

Clinical Ophthalmology is an international, peer-reviewed journal covering all subspecialties within ophthalmology. Key topics include: Optometry; Visual science; Pharmacology and drug therapy in eye diseases; Basic Sciences; Primary and Secondary eye care; Patient Safety and Quality of Care Improvements. This journal is indexed on PubMed
Central and CAS, and is the official journal of The Society of Clinical Ophthalmology (SCO). The manuscript management system is completely online and includes a very quick and fair peer-review system, which is all easy to use. Visit http://www.dovepress.com/ testimonials.php to read real quotes from published authors.

Submit your manuscript here: https://www.dovepress.com/clinical-ophthalmology-journal 